\title{
Optimal therapy in Gaucher disease
}

This article was published in the following Dove Press journal:

Therapeutics and Clinical Risk Management

2 July 2010

Number of times this article has been viewed

\section{Ozlem Goker-Alpan \\ Lysosomal Diseases Research and Treatment Unit, Center for Clinical Trials, O\&O Alpan LLC, Springfield, VA, USA}

Correspondence: Ozlem Goker-Alpan Lysosomal Diseases Research and Treatment Unit, Center for Clinical Trials, O\&O Alpan LLC, 6212 Old Keene Mill Ct, Springfield, VA, USA

Tel + I 703569 I I33

Fax +I 7035692239

Email zalpan@aol.com

\begin{abstract}
Gaucher disease (GD), the inherited deficiency of the lysosomal enzyme glucocerebrosidase, presents with a wide range of symptoms of varying severity, and primarily affects the skeletal, hematologic and nervous systems. To date, the standard of care has included enzyme replacement therapy with imiglucerase. Although imiglucerase is highly effective in reversing the visceral and hematologic manifestations, skeletal disease is slow to respond, pulmonary involvement is relatively resistant, and the CNS involvement is not impacted. Because of the recent manufacturing and processing problems, the research and development of alternative therapeutics has become more pressing. The divergent phenotypes and the heterogeneity involving different organ systems implicates the involvement of several pathological processes that include enzyme deficiency, substrate accumulation, protein misfolding, and macrophage activation, that differ in each patient with GD. Thus, the therapy should be tailored individually in order to target multiple pathways that interplay in GD.
\end{abstract}

Keywords: glucocerebrosidase, enzyme replacement therapy, substrate reduction therapy, protein misfolding and chaperone therapy, macrophage

\section{Introduction}

Gaucher disease (GD), the inherited deficiency of the lysosomal enzyme glucocerebrosidase ([GC] enzyme commission number EC 3.2.1.45), presents with a wide range of symptoms of varying severity, and primarily affects the skeletal, hematologic and nervous systems. Clinically, there are three types of GD based upon the presence and progression of the neurological symptoms. Absence of central nervous system (CNS) involvement is considered mandatory for a diagnosis of the adult form or type $1 \mathrm{GD}$, also known as nonneuronopathic GD. When there is neuronopathic involvement, the distinction between infantile, type 2 or juvenile and the type 3 form of GD, is made in the basis of age of onset and progression of CNS symptoms. While an intermediate phenotype between types 2 and 3 is also described.

The gene encoding GC (GBA, MIM\# 606463) and its homologous pseudogene are located on chromosome 1q21. ${ }^{2}$ To date, more than 250 different $G B A$ mutations, including missense, nonsense, insertions or deletions that lead to frameshift or in-frame alterations, and splice junction mutations have been identified. Recombination events with a highly homologous pseudogene downstream of the $G B A$ locus have also been reported. ${ }^{3}$ Although certain mutations, especially N370S are associated only with adult or nonneuronopathic forms, the validity of a phenotype prediction based upon genotype is quite limited. Likewise, although the homozygosity for L444P mutation 
results in neuronopathic GD, a milder clinical phenotype could be observed with very low residual enzymatic activities. ${ }^{4}$ Remarkably, phenotype and disease severity may vary among siblings, even in identical twins, and among patients carrying same mutations, a wide range of phenotypes and residual enzymatic activity are observed.,5

GC is a membrane-associated lysosomal glycoprotein. After synthesis and initial folding at a neutral $\mathrm{pH}$ in the endoplasmic reticulum, it is targeted to the lysosomes, where the acidic $\mathrm{pH}$ provides the optimal environment for stable folding and function. The majority of $G B A$ mutations lead to the synthesis of GC with decreased catalytic function and/or stability. ${ }^{6}$ While it is assumed that disease severity depends on residual GC activity, this has been difficult to prove for most $G B A$ mutations. ${ }^{7}$

GC deficiency results in the accumulation of the lipid substrate glucosylceramide. Glucosylceramide is the common intermediate resulting from lysosomal degradation of gangliosides and globosides, primarily in cells derived from monocyte-macrophage origin. The hallmark "Gaucher cells" are glucosylceramide-laden macrophages, observed in many organs, although they are predominant in bone marrow, liver spleen, and the parenchyma of lymph nodes. ${ }^{8}$ The accumulation of glucosylceramide causes enlargement of liver and spleen. Splenomegaly is associated with hypersplenism leading to anemia and thrombocytopenia. Pancytopenia is also caused by replacement of the bone marrow. Other skeletal manifestations include decreased mineralization, pathological fractures, bone pain, avascular necrosis, and painful "bone crises". 9 There is primarily radiological evidence of interstitial lung involvement, and on rare occasions pulmonary hypertension can occur. ${ }^{10}$ Additionally in children growth failure is also a common feature. ${ }^{11}$

This review will focus on the mechanisms interplaying in GD, and discuss current therapy and others, that are on the immediate horizon, that target different pathological pathways.

\section{Gaucher disease, the deficiency of the lysosomal enzyme glucocerebrosidase: recombinant enzyme therapy}

Human GC is encoded by a single locus (GBA) at chromosome 1q21. ${ }^{12}$ This lysosome-associated glycoprotein has 497 amino acids, and N-glycosylation at four or five different sites that is essential for its catalytic activity and half life. ${ }^{13}$ In the lysosome, GC catalyzes a two-step reaction that requires glycosylation of its active site by the substrate, followed by the release of beta-glucose by deglucoslation. ${ }^{14}$ To enhance in vitro activity, negatively charged phospholipids, and a naturally occurring 80 amino acid protein, saposin $\mathrm{C}$ are required. ${ }^{15}$ While there is evidence that GC physically interacts with saposin $\mathrm{C}$, the exact mechanism of saposin $\mathrm{C}$-mediated GC activation is not known. ${ }^{16}$

The resolution of the X-ray crystal structure of human GC, followed by the demonstration of a nonreversible inhibitor, conduritol $\beta$-epoxide (CBE) bound GC structure helped to understand the effects of the tertiary structure on catalytic function, and spatial relationship of $G B A$ mutations with the active site. The 3D structure with the CBE had confirmed E340 as the nucleophile and E235 as the acid-base catalyst. ${ }^{17}$ Although few mutations that are associated with a severe phenotype occur near the catalytic site, the majority of $G B A$ variants are spread through the domains of the protein. However, there is no clear relationship between the position of $G B A$ variants in the 3D structure and the disease severity. ${ }^{18}$ While the crystal structure is not available for $G B A$ mutants; among the common mutations L444, which is mutated to proline or arginine, is located at the hydrophobic core of the protein, and is predicted to produce unstable protein. ${ }^{19}$ Whereas the mutation N370S has been suggested to flank the active site, and alter interaction with saposin $\mathrm{C}$ and anionic phospholipid membranes. ${ }^{20}$

In 1964, De Duve introduced the concept of replacing the deficiency of a lysosomal enzyme. ${ }^{21}$ Proof of the general principles of enzyme replacement therapy (ERT) was developed in a model system using cocultivation of fibroblasts from patients with different types of mucopolysaccaharidosis, that corrected the enzymatic deficiency. ${ }^{22}$ Early attempts to correct the enzymatic deficiency in 1970's revealed the critical importance of $\mathrm{N}$-linked oligosaccharide chain stability of the lysosomal enzymes, and the importance of cell-type specific uptake in different diseases. The recognition signal was initially identified as mannose, and in vivo clearance of the lysosomal enzymes from plasma was found to be mediated by mannose receptors of the reticuloendothelial system. ERT quickly advanced in GD, where macrophages were regarded as the primary source for the stored abnormal lipid. ${ }^{23}$ The first enzyme preparation purified from placental tissue did not yield any significant clinical response, although the total amount of stored lipid was shown to be reduced in liver samples. ${ }^{24}$ The placental enzyme that contained complex N-linked glycans was largely taken up by the asialoglycoprotein receptors present on hepatocytes. ${ }^{25}$ Further modification of N-linked oligosaccharide terminals to remove sialic acid residues, that exposed terminal mannose residues, was essential for the 
internalization of the enzyme by the Gaucher macrophages. ${ }^{26}$ This modified high-mannose form of enzyme was readily recognized by mannose receptors abundant on the macrophages. ${ }^{27}$ The first placental derived enzyme product alglucerase (Ceredase $^{\circledR}$; Genzyme Inc, Cambridge, MA, USA) was developed based on this principle, and was tested successfully on 12 patients with type $1 \mathrm{GD}$ with improvements in hematological parameters, and the reduction in organ volumes. ${ }^{28}$ This was followed by two trials on 25 patients with imiglucerase (Cerezyme $^{\circledR}$; Genzyme Inc), a recombinant form of human GC, which differs from native $\mathrm{GC}$ with a substitution of histidine instead of arginine at position 495. Until the clinical use of ERT in 1990's, the treatment of GD consisted only of palliative measures such as splenectomy and hip replacement. The development of ERT for GD is considered to be a triumph of translational medicine. ERT is a safe and well tolerated treatment modality with only rare side effects. Currently, there are more than 5000 patients with GD that are successfully being treated with imiglucerase.

In vivo, recombinant $\mathrm{GC}$ shows high-affinity targeting to the macrophages. ${ }^{27}$ In humans and mice, imiglucerase has been shown to exhibit similar postinjection distribution patterns. The uptake of the human enzyme is primarily by the reticuloendothelial cells of the liver and spleen. In mice, post-injection enzymatic activity peaks at about 20 minutes in the liver and spleen, followed by a biphasic decrease, with a half-life around 40-60 minutes and 12-14 hours respectively. While in bone marrow, the maximal enzymatic activity is measured at 40-60 minutes. ${ }^{29}$ The uptake and tissue distribution of radio-labeled recombinant enzyme after a bolus injection was followed in patients with type 1 GD. About half of the radio-labeled enzyme was rapidly cleared from blood with a half-life less than five minutes. $30 \%$ of the injected dose was taken up immediately by the liver, about $15 \%$ by the spleen, and the bone marrow, where the half-life was over 14 hours. The remainder was cleared slowly with a half-life of between 34-42 hours. When the enzyme was administered at a higher dose, the receptor-mediated uptake was saturated, and the clearance half-life of tracer enzyme was prolonged. ${ }^{30}$

During the original clinical trial, imiglucerase was administered at a dose of $60 \mathrm{IU} / \mathrm{kg}$ every two weeks. ${ }^{28}$ There is a dose-dependent improvement in hematological and visceral parameters with alglucerase/imiglucerase. Patients with type 1 GD treated with doses more than $48 \mathrm{IU} / \mathrm{kg}$, every two weeks, were suggested to have better clinical responses. ${ }^{31}$ However, lower dose higher frequency or higher doses administered at less frequent intervals could provide similar clinical efficacy. The therapeutic threshold for macrophage-targeted GC appears to be $10-15 \mathrm{IU} / \mathrm{kg}$ every 2 weeks. Although high dose therapy provides a faster clinical response, and should be considered for patients with a more aggressive disease, the initiation of ERT at a lower dose has also led to an improvement in all nonskeletal manifestations of GD. The effects of initiating ERT at a high dose, followed by progressive dose reductions, were compared with starting the therapy at a low dose only. In patients who were started on high-dose ERT, hemoglobin, acid phosphatase, and organ volume improved or remained unchanged at the end of each dose reduction, although the platelet count decreased when the dose of enzyme was reduced to $15 \mathrm{IU} / \mathrm{kg}$. While in the treatment group that started at the minimal dose, the manifestations were similarly well controlled. ${ }^{32}$ In another study, there were no significant differences in clinical outcome when the recombinant enzyme was given at different dosing schedules including: $15 \mathrm{IU} / \mathrm{kg}$ once fortnightly or $2.5 \mathrm{IU} / \mathrm{kg}$ thrice weekly. ${ }^{34}$ Thus, smaller total doses of recombinant GC, administered frequently may have significant financial benefits, and could be considered in patients with stable type 1 GD. ${ }^{33}$ Similarly, even lower doses (7.5 IU/kg every two weeks) established good visceral and hematological response in adult patients with mild to moderate skeletal involvement. ${ }^{35}$ Despite some rare reports of treatment failures in patients with a higher disease burden, ERT administered every four weeks, was shown to be effective in most adult type 1 GD patients with stable and minimal disease. ${ }^{36,37}$ Currently, the recommendations for commencing imiglucerase treatment and subsequent dose adjustments are based on regular assessment and monitoring. Then, the maintenance of defined therapeutic goals, that include hematopoietic reconstitution, the reduction of liver and spleen volumes, together with the stabilization or improvement in skeletal findings is achieved on an individualized regimen. ${ }^{38}$ While tailoring therapy for each individual patient, several other parameters including the cost, and impact to the life style should also be taken into consideration.

In individuals with nonneuronopathic GD presentation during childhood years suggests a more severe phenotype. However many patients who are diagnosed in large-scale screenings, are mildly affected and may not require treatment. In a retrospective study, 56 children with nonneuronopathic GD, were followed up to 9 years, and only massive splenomegaly and growth retardation were found to be indications for ERT. ${ }^{39}$ In symptomatic children, however, early intervention aims to prevent the development of complications, and ensure normal growth and development through adolescence. In a large international cohort of children with GD type 1 on ERT, the longitudinal data supports the normalization of most clinical parameters including mean height, hemoglobin values 
and mean bone mineral density $z$ scores. ${ }^{40}$ Several consensus statements for treatment and monitoring of children with GD, include regular assessments, and individualized dose adjustments based on clinical response. ${ }^{41,42}$ Although a lower maintenance dose of 30-35 IU/ $/ \mathrm{kg} /$ month may be effective in most pediatric patients, more severely affected ones, especially L444P/L444P homozygotes, may require a higher maintenance dosage. ${ }^{43}$ In addition to clinical parameters, the follow up in this age group should also include evaluation of psychosocial, functional status and quality-of-life assessments. ${ }^{44}$

Although imiglucerase is highly effective in reversing the visceral and hematologic manifestations, skeletal disease is slow to respond, pulmonary involvement is relatively resistant to the enzyme, and the CNS involvement is not impacted by ERT. Some patients with type 1 GD even may experience ongoing bone disease, despite increasing doses of ERT. In such patients the ERT dose should be adjusted in order to maintain adequate visceral control, although alternative strategies including the addition of bisphosphonates could be explored. ${ }^{45}$ There is great heterogeneity in response to ERT in patients with GD and symptomatic lung involvement. Clinically, some patients benefit significantly from enzyme therapy. However, pulmonary function or radiological findings do not usually normalize, despite the correction of hematological parameters and the reduction in organ volumes. ${ }^{10}$ Although worsening pulmonary pressures have been reported after the introduction of ERT, pulmonary hypertension is associated either with poor compliance, or the lack of ERT. ${ }^{46}$ An emerging concern has been whether ERT could prevent the progression of the neurological disease in neuronopathic GD. The guidelines for the management of the neuronopathic forms of GD were recently revised. In particular, the role of high-dose ERT (120 IU/kg of body weight every 2 weeks) was analyzed. In patients receiving high-dose ERT, there was a consistent progression of brain stem findings, concomitant with the deterioration of auditory brain stem responses. ${ }^{47}$ Although high dose ERT may be required to control severe systemic symptoms, it does not stabilize neurological symptoms, and thus, is not recommended in neuronopathic GD. ${ }^{48,49}$

Other recombinant glucocerebrosidases, recently approved by the FDA or pending approval, include velaglucerase alpha (Shire HGT, Cambridge, MA, USA) and taliglucerase alpha (Protalix Biotherapeutics, Carmiel, Israel; Pfizer, NY, USA). Both have successfully completed phase III trials, and proven to be safe and clinically efficient. Although considered as biosimilars, the new recombinant GCs are not generic proteins, they are produced as novel biologicals. Imiglucerase is expressed in Chinese hamster ovary cells, where as taliglucerase is produced in transgenic carrot cells. In contrast to imiglucerase and taliglucerase, velaglucerase alpha, the gene-activated human GC, contains the native human enzyme sequence. On X-ray crystallography, all three glucocerebrosidases consist of three domains, and the active site is located in domain III, and E340 and E235 are the catalytic residues. ${ }^{50}$ Taliglucerase alpha demonstrates a high degree of homology to imiglucerase in its high-resolution three-dimensional structure, and has a bioactivity similar to imiglucerase. ${ }^{51}$ In clinical trials, velaglucerase displayed pharmacokinetic properties suggesting that the tissue distribution is linear to the doses administered. In patients, the serum concentration increased linearly with increasing doses from $15 \mathrm{IU} / \mathrm{kg}$ to $60 \mathrm{IU} / \mathrm{kg}$, and the maximum serum concentration was recorded at the end of the first hour of the infusion. ${ }^{52}$ Although velaglucerase has a specific activity comparable with imiglucerase, the cellular uptake is suggested to be more efficient due to differences in glycosylation. Imiglucerase contains a chitobiose tri-mannosyl core glycan with fucosylation, while velaglucerase predominantly displays high-mannose type glycans with nine mannose units. The differences in glycosylation are suggested to affect better internalization into human macrophages. ${ }^{50}$ Taliglucerase is targeted to the storage vacuoles using a plant-specific C-terminal sorting signal, that naturally contains terminal mannose residues in its complex glycans. Thus, taliglucerase does not require exposure of mannose residues in vitro, which is a requirement for the production of other recombinant GCs. ${ }^{53}$ Nevertheless, higher number of mannose residues may result in increased immunogenicity due to the presentation of nonmammalian glycans. ${ }^{54}$ However, there have been no clinical adverse effects, nor increased frequency of neutralizing antibodies associated with taliglucerase during safety and pharmacokinetics studies. ${ }^{54}$ Recently, there has been serious problems in the manufacturing and processing of imiglucerase, and availability of alternative therapeutics has become more pressing than ever. Having different enzymes for therapeutic use will provide an opportunity to re-evaluate indications and initiation of ERT, management of nonresponders, and a cost-benefit maintenance therapy.

\section{Gaucher disease, a storage disorder of the lysosomes: substrate reduction therapy (SRT)}

The pathophysiology of lysosomal storage diseases is not completely understood and there is no doubt that the abnormal substrate accumulation, the triggering 
secondary biochemical and cellular events, is one of the primary the pathogenic factors. In GD, glucosylceramide accumulates in the lysosomes, it is not known whether the cellular pathology is related to the lysosomal dysfunction secondary to storage, or whether glucosylceramide escapes from the lysosome and interacts with other organelles. In macrophages, for example, glucosylceramide accumulation is suggested to cause enhanced phagocytic activity. ${ }^{55}$ Glucosylceramide accumulates in tissues, and is elevated in the plasma of patients with GD, the amount is not significant. ${ }^{56}$ While ERT is aimed to remove the accumulation of storage material within the lysosome, SRT targets the biosynthetic cycle to partially reduce the load of substrate influx to the lysosome, which is already catabolically compromised. Miglustat (Zavesca $^{\circledR}$; Actelion Ltd, Basel Switzerland) is an imino sugar that reversibly inhibits the critical step in glycosphingolipid synthesis, and has been approved as the first oral SRT agent. During the trials, there was a significant reduction in organ volumes, although the improvement in hematological parameters was less significant, and thus, miglustat is recommended primarily for adult patients with GD type1, who are unable or unwilling to be on ERT. ${ }^{57}$ However, significant side effects such as loose stools, tremor and peripheral neuropathy have limited its therapeutic use. ${ }^{58}$ Currently attempts are ongoing to develop other glucosylceramide inhibitors, and a phase III clinical trial is being conducted to evaluate the efficacy, safety, and pharmacokinetics of a novel SRT molecule in adult patients with GD type 1 (ClinicalTrials.gov identifier: NCT00891202). Unlike recombinant enzymes, SRT agents are small molecules that can cross the blood-brain barrier. ${ }^{59}$ Although improved pulmonary function, and a significant decrease in chitotriosidase levels have been observed in patients with GD type 3, miglustat unfortunately, does not appear to have any significant benefits on the neurological manifestations of GD. ${ }^{60}$

Glycosphingolipids affect a variety of cellular functions, and long term SRT may theoretically alter several pathways in the cell, and therefore, should be approached with great clinical care. ${ }^{61}$

\section{Gaucher disease, a protein misfolding disorder: pharmacological chaperones and enzyme enhancement therapy (EET)}

The majority of $G B A$ mutations are missense, leading to the synthesis of GC with decreased catalytic function and/or stability. ${ }^{3}$ At the cellular level, missense mutations can result in altered processing or a conformational change in the mutant protein leading to a toxic gain-of-function. ${ }^{62,63}$ Protein misfolding contributes to the pathophysiology of several genetic and sporadic diseases. A prime example for proteinopathies is the adult-onset neurodegenerative diseases, where diverse molecular mechanisms result in the abnormal accumulation of proteins in the nervous system. Parkinson disease is the prototype adult-onset neurodegenerative disorder, characterized by the abnormal accumulation alphasynuclein that results in intraneuronal aggregates and cell death. ${ }^{64}$ Clinical, genetic and neuropathologic observations have shown that $G B A$ mutations constitute a risk factor for the development of parkinsonian manifestations, thus leading to the hypothesis that protein misfolding may play a role in the phenotypes associated with GD. ${ }^{65-67}$

"Pharmacological chaperones" are small molecules that bind to misfolded proteins, and assist their correct refolding and/or maturation. Chaperone or EET is an attractive approach because of its potential for simple oral administration, penetration of the blood-brain barrier, and its low cost. EET has been proposed for a number of lysosomal storage disorders, including GD, Sandhoff, Fabry, and Tay-Sachs diseases. ${ }^{68,69}$ The mechanism of action for these compounds is competitive binding to the active site of the mutant enzyme, facilitating proper folding and trafficking to the lysosome, where endogenous substrate displaces the chaperone and enzyme activity is restored. ${ }^{70}$ Most chaperones studied to date are enzyme inhibitors in the structural class of imino sugars or similar analogs of the natural substrate, glucosylceramide. ${ }^{71}$ Imino sugars have been shown to increase the cellular activity of the N370S mutant form of GC, as well as the wild-type enzyme. ${ }^{72}$ In cell based systems, where fibroblasts from patients are cultured with the chemical chaperone N-nonyl-deoxynojirimycin, the enzymatic activity of the GC variant, N370S, is increased. Similarly G202R, a GC variant retained in the endoplasmic reticulum, is also shown to be amenable to chemical chaperoning. ${ }^{73}$ However, imino sugar derivatives are nonspecific and have relatively short half-lives in cells, and these molecules can inhibit other glycolipid and glycoprotein processing enzymes. ${ }^{74}$ Several studies have demonstrated that isofagomine (IFG), an imino sugar that binds to the active site, enhanced the folding, transport, and stability of several GC variants, including L444P. ${ }^{75}$ IFG was found to have little or no inhibitory activity against other glucosidases, and further treatment of wild type fibroblasts with high doses did not alter the processing of newly synthesized N-linked oligosaccharides. ${ }^{76}$ These findings supported the further evaluation of IFG as a potential therapeutic 
agent in GD. Despite promising in vivo results, and safety data (Clinical Trials.gov Identifier: NCT00433147), clinically meaningful improvements in key measures of the disease were not adequate. There are no plans to advance this chaperone further into a phase III trial. In addition to imino sugars, calcium channel blockers are suggested to act as pharmacologic chaperones through altered calcium homeostasis, and are shown to partially restore mutant GC activity. ${ }^{77}$ While diltiazem exhibited the properties of a pharmacological chaperone at neutral $\mathrm{pH}$, of the endoplasmic reticulum in cell-based systems, in animal studies these effects were minor. ${ }^{78,79}$

Screening large compound libraries by quantitative high-throughput screening (qHTS) provides comprehensive information on the potency, efficacy, and structure-activity relationships of active compounds, facilitating identification of leads for medicinal chemistry optimization. qHTS was used to rapidly identify different nonsugar GC inhibitors. ${ }^{80}$ Similarly, screening a library of FDA-approved drugs using a thermal denaturation assay identified Ambroxol (a drug used to treat airway mucus hypersecretion and hyaline membrane disease in newborns) as a pH-dependent, mixed-type inhibitor of GC. Ambroxol demonstrates the characteristics of an EET agent through its interaction with both active and nonactive sites, and may have the potential to move towards clinical trials. ${ }^{81}$

Although EET is promising to treat CNS manifestations, in vitro studies has shown that pharmacological chaperones are mostly mutation specific, and they may not be suitable for every patient with GD. Long-term clinical trials are required to test the in vivo effects of different chaperones on the specific disease pathology that could be associated with protein misfolding.

\section{Gaucher disease, a macrophage disorder}

GD was described more than a century ago by the identification of lipid engorged macrophages, referred to as "Gaucher cells", were periodic acid Schiff-positive cells with wrinkledtissue paper like appearance. GD has been regarded primarily as a macrophage disorder; however, current knowledge renders this classification too simplistic. Gaucher cells are not inert storage cells, they are metabolically active and secrete various proteins. In the plasma of patients with GD, the levels of macrophage/monocyte activation markers such as soluble CD14 and CD 163 are elevated. ${ }^{82}$ Gaucher cells strongly express markers of alternative activation, such as interleukin-1 antagonist and CCL18, which are anti-inflammatory molecules. ${ }^{83}$ Other biochemical correlates of GD represent hydrolases, localized to storage cells and/or surrounding macrophages, such as tartrate-resistant acid phosphatase and angiotensin-converting enzyme. ${ }^{84,85}$ These biomarkers, however, are nonspecific, and are altered in a number of disorders that affect the reticuloendothelial system. Furthermore, the overlap between the levels of hydrolases between patients with GD and healthy controls restrict their clinical use. ${ }^{86}$ In the plasma of symptomatic GD patients, biochemical investigations demonstrated a more than 1000-fold increase of a class of chitinases, named "chitotriosidase". Chitotriosidase originates from macrophages, and stored lipid is the major inducer. ${ }^{87}$ Macrophages are also the primary source for another cytokine, CCL18, which has been found to be elevated in GD. ${ }^{88}$ Both these surrogate markers are not organ specific, although they may reflect overall disease burden, and respond to therapeutic response. ${ }^{89}$ While the exact contribution of chitotriosidase and CCL18 to the disease pathophysiology remains to be elucidated, the pulmonary, skeletal and immune system involvement in GD may have a closer association with the activation and release of different cytokines from the macrophage-monocyte system. During the chronic inflammatory process, as is observed in some patients with GD, the balance between bone formation and resorption is skewed toward osteoclast-mediated bone resorption, which may explain osteopenia commonly observed in patients with GD. ${ }^{90-92}$ Macrophage activation is the common denominator in multiple disorders, characterized by radiological evidence of interstitial pulmonary involvement. While chitotriosidase is one of the established biomarkers for GD, it has been recently used as an indicator in alveolar lung diseases, such as sarcoidosis and miliary tuberculosis. ${ }^{93,94}$ Chitotriosidase levels are shown to be significantly higher in patients with idiopathic interstitial lung disease. ${ }^{95}$

Surrogate markers in GD serve only as indicators of macrophage activation, and should not be used as diagnostic tools. Macrophages participate in the autoregulatory loop of the inflammatory process, and produce a wide range of biologically active molecules participating in both the beneficial and detrimental outcomes in inflammation. The inflammatory component in GD may play a role in the development and progression of bone, pulmonary and neurological complications. Therapeutic interventions that target macrophages and their products may open new avenues in the treatment of GD.

\section{Conclusion}

Although GD is considered to be a "simple Mendelian disorder", divergent phenotypes and the heterogeneity involvement of different organ systems in each patient with GD implicate the role 
of different pathological pathways. Thus the optimal therapeutic expectations may differ in each patient with GD. Despite better tissue penetration and alternative mechanisms of action of novel therapeutics what is potentially achievable and what is likely to remain irreversible in GD manifestations will be contingent upon multiple factors such as genetic and environmental modifiers. The bone and secondary neurological manifestations in adultonset GD may serve as examples for some perceived limitations of clinical management in GD. Although the ultimate aim is to treat all skeletal manifestations, such as the reversal of osteopenia and to prevent and treat bone crises, a clinician who follows a number of patients with GD will be aware that some patients will progressively lose bone mineral density or develop new bone lesions, despite a maximum dose ERT, diet supplements or weight-bearing exercises. The establishment of the association between $G B A$ mutations and the development of parkinsonian manifestations have brought new challenges for both the clinician and researchers. There are several lines of evidence that suggest there is an association between $G B A$ mutations and development of Parkinson disease pathology. ${ }^{96,97}$ Although the risk of Parkinson disease is suggested to be increased, especially among individuals carrying "severe" $G B A$ mutations, the penetrance and again the role of modifiers are not known for each GBA alteration..$^{98}$ Furthermore, $99 \%$ of individuals carrying $G B A$ mutations either in hetero- or homozygote states will not develop parkinsonian manifestations, limiting the genetic counseling even in "at risk" individuals in families with more than one person affected. The current recommended therapy for $G B A$-associated parkinsonism is limited to the standard parkinsonian therapy, when the symptoms are L-dopa responsive, and testing for $G B A$ mutations remains an academic endeavor more than that of a risk and prognostic determinant.

The future of the treatment of GD will include an individualized approach, employing a combination of therapies that can address the effects of enzyme deficiency, storage of abnormal lipid substrate resulting in lysosomal dysfunction, protein misfolding and the inflammatory processes.

\section{Disclosure}

The author reports no conflicts of interest relevant to this research.

\section{References}

1. Goker-Alpan O, Schiffmann R, Park JK, Stubblefield BK, Tayebi N, Sidransky E. Phenotypic continuum in neuronopathic Gaucher disease: an intermediate phenotype between type 2 and type 3. J Pediatr. 2003; 143:273-276.

2. Barneveld RA, Keijzer W, Tegelaers FP, et al. Assignment of the gene coding for human beta-glucocerebrosidase to the region q21-q31 of chromosome 1 using monoclonal antibodies. Hum Genet. 1893;64:227-231.
3. Hruska KS, LaMarca ME, Scott CR, Sidransky E. Gaucher disease: mutation and polymorphism spectrum in the glucocerebrosidase gene (GBA). Hum Mutat. 2008;29:567-583.

4. Goker-Alpan O, Hruska KS, Orvisky E, et al. Divergent phenotypes in Gaucher disease implicate the role of modifiers. J Med Genet. 2005;42:e37.

5. Lachmann RH, Grant IR, Halsall D, Cox TM. Twin pairs showing discordance of phenotype in adult Gaucher's disease. QJM. 2004; 97:199-204.

6. Hruska KS, LaMarca ME, Sidransky E. In: Gaucher Disease. Futerman AH, Zimran A, editors. Boca Raton, FL: CRC Press; 2006. p. 13-48.

7. Beutler E, Grabowski GA, Scriver CR, Beaudet AL, Valle D, Sly WS, (editors), In: The Metabolic and Molecular Bases of Inherited Diseases. New York, NY: McGraw-Hill; 2001.

8. Conradi NG, Kalimo H, Sourander P. Reactions of vessel walls and brain parenchyma to the accumulation of Gaucher cells in the Norrbottnian type (type III) of Gaucher disease. Acta Neuropathologica. 2004; 75:385-390.

9. Wenstrup RJ, Roca-Espiau M, Weinreb NJ, Bembi B. Skeletal aspects of Gaucher disease: a review. Br J Radiol. 2002;75 Suppl 1:A2-A12.

10. Goitein $\mathrm{O}$, Elstein D, Abrahamov A, et al. Lung involvement and enzyme replacement therapy in Gaucher's disease. Q J Med. 2001;94:407-415.

11. Kaplan P, Andersson HC, Kacena KA, Yee JD. The clinical and demographic characteristics of non-neuronopathic Gaucher disease in 887 children at diagnosis. Arch Pediatr Adolesc Med. 2006; 160:603-608.

12. Ginns EI, Choudary PV, Tsuji S, et al. Gene mapping and leader polypeptide sequence of human glucocerebrosidase: implications for Gaucher disease. Proc Natl Acad Sci U S A. 1985;82:7101-7105.

13. Berg-Fussman A, Grace ME, Ioannou Y, Grabowski GA. Human acid beta-glucosidase. N-glycosylation site occupancy and the effect of glycosylation on enzymatic activity. J Biol Chem. 1993;268:14861-14866.

14. Grabowski GA, Gatt and Horowitz M. Acid $\beta$-glucosidase: enzymology and molecular biology of Gaucher disease. Crit Rev Biochem Mol Biol. 1990;25:385-414.

15. Vaccaro AM, Tatti M, Ciaffoni F, Salvioli R, Barca A, Scerch C. Effect of saposins A and $\mathrm{C}$ on the enzymatic hydrolysis of liposomal glucosylceramide. J Biol Chem. 1990;272:16862-16867.

16. Morimoto S, Kishimoto Y, Tomich J, et al. Interaction of Saposins, Acid Lipids, and Glucosylceramidase. J Biol Chem. 1990;265:1933-1937.

17. Premkumar L, Sawkar AR, Boldin-Adamsky S, et al. X-ray structure of human acid beta-glucosidase covalently bound to conduritol- $\beta$-epoxide. Implications for Gaucher disease. J Biol Chem. 2005; 280:23815-23819.

18. Dvir H, Harel M, McCarthy AA, et al. X-ray structure of human acid $\beta$-glucosidase, the defective enzyme in Gaucher disease. EMBO Rep. 2003;2003: 704-709.

19. Grace ME, Graves PN, Smith FI, Grabowski GA. Analysis of catalytic and inhibitor binding of human acid beta-glucosidase by site directed mutagenesis. J Biol Chem. 1994;256:6827-6835.

20. Salvioloi R, Tatti M, Scarpa S, et al. The N370S $\left(\mathrm{Asn}^{370}\right.$ Ser) mutation affects the capacity of glucosylceramidase to interact with anionic phospholipid-containing membranes and saposin C. Biochem J. 2005; 390:95-103.

21. De Duve C. From cytases to hydrolases. Federation Proceedings. 1964; 23:1045-1049.

22. Frantoni JC, Hall CW, Neufeld EF. Hurler and Hunter syndromes: mutual correction of the defect in cultured fibroblasts. Science. 1968;162:468-572.

23. Brady RO, Pentchev PG, Gal AE, Hibbert SR, Dekaban AS. Replacement therapy for inherited enzyme deficiency. Use of purified glucocerebrosidase in Gaucher's disease. N Engl J Med. 1974;291:989-993.

24. Furbish FS, Steet CJ, Barranger JA, Jones EA, Brady RO. The uptake of naive and desialylated glucocerebrosidase by rate hepatocytes and Kupffer cells. Biochem Biophys Res Commun. 1978;81:1047-1053.

25. Beutler E, Kuhl W, Vaughan LM. Failure of alglucerase infused into Gaucher disease patients to localize in marrow macrophages. Mol Med. $1995 ; 1: 320-324$. 
26. DoebberTW, Wu MS, Bugianesi RL, et al. Enhanced macrophage uptake of synthetically glycosylated human placental $\beta$-glucocerebrosidase. J Biol Chem. 1982;252:2193-2199.

27. Sato Y, Beutler E. Binding, internalization and degradation of mannose terminated glucocerebrosidase by macrophages. J Clin Invest. 1993; 91:1909-1917.

28. Barton NW, Brady RO, Dambrosia JM, et al. Replacement therapy for inherited enzyme deficiency-macrophage targeted glucocerebroidase for Gaucher's disease. N Engl J Med. 1991;234:1464-1470.

29. Xu YH, Ponce E, Sun Y, Leonova T, Bove K, Witte D, Grabowski GA. Turnover and distribution of intravenously administered mannoseterminated human acid beta-glucosidase in murine and human tissues. Pediatr Res. 1996;39:313-322.

30. Mistry PK, Wraight EP, Cox TM. Therapeutic delivery of proteins to macrophages:Implications for treatment of Gaucher's disease. Lancet. 1996;348:1555-1559.

31. Grabowski GA, Kacena K, Cole JA, et al. Dose response relationships for enzyme replacement therapy with imiglucerase/aglucerase in patients with Gaucher disease type 1. Genet Med. 2009; 11:92-100.

32. Altarescu G, Schiffmann R, Parker CC, et al. Comparative efficacy of dose regimens in enzyme replacement therapy of type I Gaucher disease. Blood Cells Mol Dis. 2000;26:285-290.

33. Figueroa ML, Rosenbloom BE, Kay AC, et al. A less costly regimen of aglucerase to treat Gaucher's disease. N Engl J Med. 1992; 327:1632-1636.

34. Zimran A, Hadas-Halpern I, Zevin S, Levy-Lahad E, Abrahamov A. Low-dose high-frequency enzyme replacement therapy for very young children with severe Gaucher disease. Br J Haematol. 1993; 85:783-786.

35. Wilson C, Spearing R, Teague L, Robertson P, Blacklock H. The outcome of clinical parameters in adults with severe Type I Gaucher disease using very low dose enzyme replacement therapy. Mol Genet Metab. 2007;92:131-136.

36. de Fost M, Aerts J, Groener JEM, et al. Low frequency maintenance therapy with imiglucerase in adult type I Gaucher disease: a prospective randomized controlled trial. Haematologica. 2007;92:215-221.

37. Kishnani PS, DiRocco M, Kaplan P, et al. A randomized trial comparing the efficacy and safety of imiglucerase (Cerezyme) infusions every 4 weeks versus every 2 weeks in maintenance therapy of adult patients with Gaucher disease type 1. Mol Genet Metab. 2009;96:164-170.

38. Pastores GM, Weinreb NJ, Aerts G, et al. Semin Hematol. 2004;41 Suppl $5: 4-14$.

39. Dweck A, Abrahamov A, Hadas-Halpern I, Bdolach-Avram T, Zimran A, Elstein D. Type I Gaucher disease in children with and without enzyme therapy. Pediatr Hematol Onco. 2002;6:389-397.

40. Andersson H, Kaplan P, Kacena K, Yee J. Eight-year clinical outcomes of long-term enzyme replacement therapy for 884 children with Gaucher disease Type 1. Pediatrics. 2008;122:1182-1190.

41. Charrow J, Andersson HC, Kaplan P, et al. Enzyme replacement therapy and monitoring for children with type 1 Gaucher disease: consensus recommendations. J Pediatr. 2004;144:112-120.

42. Grabowski GA, Andria G, Baldellou A, et al. Pediatric non-neuronopathic Gaucher disease: presentation, diagnosis and assessment. Consensus statements. Eur J Pediatr. 2004;163:58-66.

43. Brunel-Guitton C, Rivard GE, Galipeau J, et al. Enzyme replacement therapy in pediatric patients with Gaucher disease: what should we use as maintenance dosage? Mol Gen Metab. 2009;96:73-76.

44. Baldellou A, Andria G, Campbell PE, et al. Paediatric non-neuronopathic Gaucher disease: recommendations for treatment and monitoring. Eur J Pediatr. 2004;163:67-75.

45. de Fost M, van Noesel CJM, Johannes MFG, et al. Persistent bone disease in adult type 1 Gaucher disease despite increasing doses of enzyme replacement therapy. Hematologica. 2008;93:119-1120.

46. Mistry PK, Sirrs S, Chan A, et al. Pulmonary hypertension in type 1 Gaucher's disease: genetic and epigenetic determinants of phenotype and response to therapy. Mol Genet Metab. 2002;77:91-98.
47. Campbell PE, Harris CM, Vellodi A. Deterioration of the auditory brainstem response in children with type 3 Gaucher disease. Neurology. 2004:63:385-387

48. Vellodi A, Tylki-Szymanska A, Davies EH, et al. Management of neuronopathic Gaucher disease: revised recommendations. J Inherit Metab Dis. 2009;32:660-664.

49. Schiffmann R, Heyes MP, Aerts JM, et al. Prospective study of neurological responses to treatment with macrophage-targeted glucocerebrosidase in patients with type 3 Gaucher's disease. Ann Neurol. 1997;42:613-621.

50. Brumshtein B, Salinas P, Peterson B, et al. Characterization of geneactivated human acid- $\beta$-glucosidase:crystal structure, glycan composition and internalization into macrophages. Glycobiology. 2010; 20:24-32.

51. Shaaltiel Y, Bartfeld D, Hashmueli S, et al. Production of glucocerebrosidase with terminal mannose glycans for enzyme replacement therapy of Gaucher's disease using a plant cell system. Plant Biotechnol J. 2007; 5:579-590

52. Zimran A, Loveday K, Fratazzi C, Elstein D. A pharmacokinetic analysis of a novel enzyme replacement therapy with gene-activated human glucocerebrosidase (GA-GCB) in patients with type 1 Gaucher disease. Blood Cells Mol Dis. 2007;39:115-118.

53. Scott M. van Patten SM, Hughes H, et al. Effect of mannose chain length on targeting of glucocerebrosidase for enzyme replacement therapy of Gaucher disease. Glycobiology. 2007;17:467-478.

54. Aviezer D, Brill-Almon E, Yoseph Shaaltiel Y, et al. Plant-derived recombinant human glucocerebrosidase enzyme - a preclinical and phase I investigation. PLoS ONE. 2009;4:e4792.

55. Penneli N, Scaravilli F, Zacchello F. Morphogenesis of Gaucher cells investigated by electron microscopy. Blood. 1969;34:331-347.

56. Nillson O, Hakansson G, Dreborg S, Groth CG, Svernerholm L. Increased cerebroside concentration in plasma and erythrocytes in Gaucher disease: significant differences between type I and type III. Clin Gene. 1982;22:274-279.

57. Cox T, Lachmann R, Hollak CM, et al. Novel oral treatment of Gaucher's disease with N-butyldeoxynojirimycine (OGT 918) to decrease substrate biosynthesis. Lancet. 2000;355:1481-1485.

58. Hollak CEM, Hughes D, van Schaik IV, Schwierin B, Bembi B. Miglustat $\left(\right.$ Zavesca $\left.^{\circledR}\right)$ in type 1 Gaucher disease: 5 -year results of a post-authorization safety. Pharmacoepidem Dr S. 2009;18:770-777.

59. Platt FM, Neises GR, Reikenmeiser G, et al. Prevention of lysosomal storage disease in Tay Sachs mice treated with N-butyldeoxynojirimycin. Science. 1997;276:428-431.

60. Shiffmann R, FitzGibbon EJ, Harris C, et al. Randomized, controlled trial of miglustat in Gaucher's disease Type 3. Ann Neurol. 2008;64:514-522.

61. Futerman $\mathrm{AH}$ and Hannun YA, The complex life of simple sphingolipids. EMBO Rep. 2004;5:777-782.

62. Thompson A, Barrow CJ. Protein conformational misfolding and amyloid formation: characteristics of a new class of disorders that include Alzheimer's and prion diseases. Curr Med Chem. 2002;9: 1751-1762.

63. Gregersen N. Protein misfolding disorders: pathogenesis and intervention. J Inherit Metab Dis. 2006;29:456-470.

64. Chiti F, Dobson CM. Protein misfolding, functional amyloid, and human disease. Annu Rev Biochem. 2006;75:333-366.

65. Lwin A, Orvisky E, Goker-Alpan O, LaMarca ME, Sidransky E. Glucocerebrosidase mutations in subjects with parkinsonism. Mol Genet Metab. 2004;81:70-73.

66. Goker-Alpan O, Schiffmann R, LaMarca ME, Nussbaum RL, McInerneyLeo A, Sidransky E. Parkinsonism among Gaucher disease carriers. J Med Genet. 2004;41:937-940.

67. Goker-Alpan O, Giasson BI, Eblan MJ, et al. Glucocerebrosidase mutations are an important risk factor for Lewy body disorders. Neurology. 2006;67:908-910.

68. Fan JQ. A contradictory treatment for lysosomal storage disorders: inhibitors enhance mutant enzyme activity. Trends Pharmacol Sci. $2003 ; 24: 355-360$. 
69. Butters TD. Pharmacotherapeutic strategies using small molecules for the treatment of glycolipid lysosomal storage disorders. Expert Opin Pharmacother. 2007;8:427-435.

70. Sawkar AR, Cheng WC, Beutler E, Wong CH, Balch WE, Kelly JW. Chemical chaperones increase the cellular activity of N370S $\beta$-glucosidase: a therapeutic strategy for Gaucher disease. Proc Natl Acad Sci U S A. 2002;99:15428-31543.

71. Chang HH, Asano N, Ishii S, Ichikawa Y, Fan JQ. Hydrophilic imino sugar active-site-specific chaperones increase residual glucocerebrosidase activity in fibroblasts from Gaucher patients. FEBS J. 2006;273: 4082-4092.

72. Steet RA, Chung S, Wustman B, Powe A, Do H, Kornfeld SA. The imino sugar isofagomine increases the activity of N370S mutant acid $\beta$-glucosidase in Gaucher fibroblasts by several mechanisms. Proc Natl Acad Sci U S A. 2006;103:13813-13818.

73. Sawkar AR, Adamski-Werner SL, Cheng WC, et al. Gaucher diseaseassociated glucocerebrosidases show mutation-dependent chemical chaperoning profiles. Chem Biol. 2005;12:1235-1244.

74. Stanley P, Sundaram S, Tang J, Shi S. Molecular analysis of three gainof-function CHO mutants that add the bisecting GlcNAc to N-glycans. Glycobiology. 2005;15:43-53.

75. Khanna R, Benjamin ER, Pellegrino L, et al. The pharmacological chaperone isofagomine increases the activity of the Gaucher disease L444P mutant form of beta-glucosidase. FEBS J. 2010;277(7)1618-1638.

76. Steet R, Chung S, Lee WS, Pine CW, Do H, Kornfeld S. Selective action of the imino sugar isofagomine, a pharmacological chaperone for mutant forms of acid-beta-glucosidase. Biochem Pharmacol. 2007;73:1376-1383.

77. Mu TW, Fowler DM, Kelly JW. Partial restoration of mutant enzyme homeostasis in three distinct lysosomal storage disease cell lines by altering calcium homeostasis. PLoS Biol. 2008;6:e26.

78. Rigat B, Mahuran D. Diltiazem, a L-type $\mathrm{Ca}(2+)$ channel blocker, also acts as a pharmacological chaperone in Gaucher patient cells. Mol Genet Metab. 2009;96:225-232.

79. Sun Y, Liou B, Quinn B, Ran H, Xu YH, Grabowski GA. In vivo and ex vivo evaluation of L-type calcium channel blockers on acid beta-glucosidase in Gaucher disease mouse models. PLoS One. 2009; 4:e7320.

80. Zheng W, Padia J, Urban DJ, et al. Three classes of glucocerebrosidase inhibitors identified by quantitative high-throughput screening are chaperone leads for Gaucher disease. PNAS. 2007;104:13192-13197.

81. Maegawa GH, Tropak MB, Buttner JD, et al. Identification and characterization of ambroxol as an enzyme enhancement agent for Gaucher disease. J Biol Chem. 2009;284:23502-23516.

82. Moller HJ, DeFost M, Aerts H, Hollak C, Moestrup SK. Plasma level of the macrophage-derived soluble CD163 is increased and positively correlates with severity in Gaucher's disease. Eur J Haematol. 2004; 72:135-139.
83. Boven LA, van Meurs M, Boot RG, et al. Gaucher cells demonstrate a distinct macrophage phenotype and resemble alternatively activated macrophages. Am J Clin Pathol. 2004;122:359-369.

84. Douglas B, Robinson RH, Glew A. Tartrate-resistant acid phosphatase from gaucher spleen. J Biol Chem. 1980;255:5864-5870.

85. Silverstein E, Pertschuk LP, Friedland J. Immunofluorescent detection of angiotensin-converting enzyme (ACE) in Gaucher cells. Am J Med. 1980;69:408-410.

86. Hollak CEM, Maas M, Aerts JM. Clinically relevant therapeutic endpoints in type I Gaucher disease. J Inherit Metab Dis. 2001; 24 Suppl 2:97-105.

87. Hollak CE, van Weely S, van Oers MH, Aerts JM. Marked elevation of plasma chitotriosidase activity: a novel hallmark of Gaucher disease. J Clin Invest. 1994;93:1288-1292.

88. Boot RG, Verhoek M, Langeveld M, et al. CCL18: a urinary marker of Gaucher cell burden in Gaucher patients. J Inherit Metab Dis. 2006; 29(4):564-571.

89. Aerts JM, van Breemen MJ, Bussink AP, et al. Biomarkers for lysosomal storage disorders: identification and application as exemplified by chitotriosidase in Gaucher disease. Acta Paediatr. 2008;97:7-14.

90. Moran MT, Schofield JP, Hayman AR, Shi GP, Young E, Cox TM. Pathologic gene expression in Gaucher disease: up-regulation of cysteine proteinases including osteoclastic cathepsin K. Blood. 2000; 96:1969-1978.

91. Rogowski O, Shapira I, Zimran A, et al. Automated system to detect low-grade underlying inflammatory profile: Gaucher disease as a model. Blood Cells Mol Dis. 2005;34:26-29.

92. Herman S, Krönke G, Schett G. Molecular mechanisms of inflammatory bone damage, emerging trends for therapy. Trends $\mathrm{Mol} \mathrm{Med}$. 2008;14(6):245-253.

93. Bargagli E, Margollicci M, Nikiforakis N, et al. Chitotriosidase activity in the serum of patients with sarcoidosis and pulmonary tuberculosis. Respiration. 2007;74:548-552.

94. Boot RG, Hollak CE, Verhoek M, Alberts C, Jonkers RE, Aerts JM. Plasma chitotriosidase and CCL18 as surrogate markers for granulomatous macrophages in sarcoidosis. Clin Chim Acta. 2010;411:31-36.

95. Bargagli E, Maggiorelli C, Rottoli P, Chitotriosidase in patients with interstitial lung disease. Respiration. 2008;76:234-238.

96. Goker-Alpan O, Giasson BI, Eblan MJ, et al. Glucocerebrosidase mutations are an important risk factor for Lewy body disorders. Neurology 2006;67:908-910.

97. Goker-Alpan O, Lopez G, Vithayathl J, Davis J, Hallett M, Sidransky E. The spectrum of parkinsonian manifestations associated with glucocerebrosidase mutations. Arch Neurol. 2008;65:1353-1357.

98. Gan-Or Z, Giladi N, Rozovski U, et al. Genotype-phenotype correlations between $G B A$ mutations and Parkinson disease risk and onset Neurology. 2008;70:2277-2283.
Therapeutics and Clinical Risk Management

\section{Publish your work in this journal}

Therapeutics and Clinical Risk Management is an international, peerreviewed journal of clinical therapeutics and risk management, focusing on concise rapid reporting of clinical studies in all therapeutic areas, outcomes, safety, and programs for the effective, safe, and sustained use of medicines. This journal is indexed on PubMed Central, CAS,

\section{Dovepress}

EMBase, Scopus and the Elsevier Bibliographic databases. The manuscript management system is completely online and includes a very quick and fair peer-review system, which is all easy to use. Visit http://www.dovepress.com/testimonials.php to read real quotes from published authors. 